Published in: Journal of Constructional Steel Research, 67(10), 1545-1553.

DOI: http://dx.doi.org/10.1016/j.jcsr.2011.03.027

\title{
Steel silos with different aspect ratios: II - behaviour under eccentric discharge
}

\author{
A.J. Sadowski \& J.M. Rotter
}

\begin{abstract}
The phenomenon of eccentric discharge is widely recognised as the most dangerous condition for thin-walled metal silos and the cause of many catastrophic buckling failures. A realistic pressure model for this condition appears in a regulating standard for the first time in EN 1991-4 (2006) on Actions on Silos and Tanks. However the structural consequences of its application are currently largely unknown. The behaviour of a silo subjected to these pressures is certainly very dependent on the aspect ratio of the silo, the granular solid properties and the discharge channel geometry.
\end{abstract}

This paper explores the behaviour of four thin-walled cylindrical silos with stepwisevarying wall thickness and aspect ratios varying from intermediate to very slender, subject to the codified EN 1991-4 eccentric discharge pressures. It is shown that a silo design that was found to be very safe under the EN 1991-4 concentric discharge pressures becomes very unsafe under eccentric discharge. Further, as it is known that the aspect ratio has an important effect on the flow pattern in discharging granular solids, and that slender silos exhibit very different flow patterns from squat silos, it is currently not certain whether a suitable range of aspect ratio over which the codified eccentric discharge model is to be applied has been prescribed in the standard.

This paper is the second of a pair. In the first, the behaviour of a set of example silos under the EN 1991-4 concentric discharge condition was studied. The same example silos are studied here under eccentric discharge.

Keywords: eccentric discharge; silos, aspect ratio; shell buckling; finite element analysis; shells under unsymmetrical pressures. 
Published in: Journal of Constructional Steel Research, 67(10), 1545-1553.

DOI: http://dx.doi.org/10.1016/j.jcsr.2011.03.027

\section{Introduction}

The phenomenon of eccentric discharge is widely understood to be the most serious loading condition for a thin-walled metal silo, and the cause of many catastrophic buckling failures in the past. The associated patterns of normal pressures and frictional tractions exerted by the eccentrically flowing granular solid are known to produce very unsymmetrical patterns of stresses in the silo wall, which precipitate early buckling failure (Rotter, 1986; 2001a; 2001b; Sadowski \& Rotter, 2010; 2011). With recent advances in the power of both computers and the finite element method, it is now possible to undertake nonlinear analyses of thin metal silos under complex load patterns that were extremely difficult only a decade ago.

Key:

1) Internal (taper) pipe flow

2) Mixed flow

3) Eccentric taper pipe flow

4) Eccentric parallel pipe flow

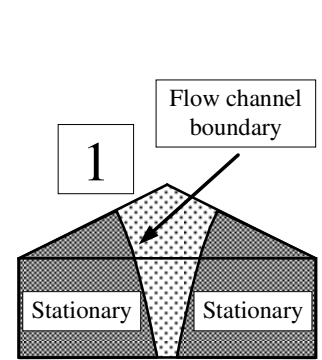

Retaining silo

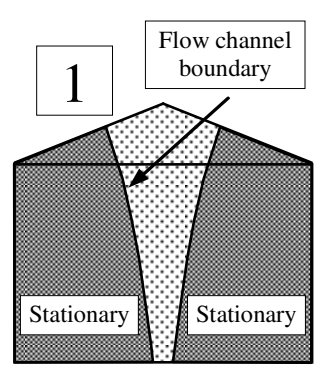

Squat silo

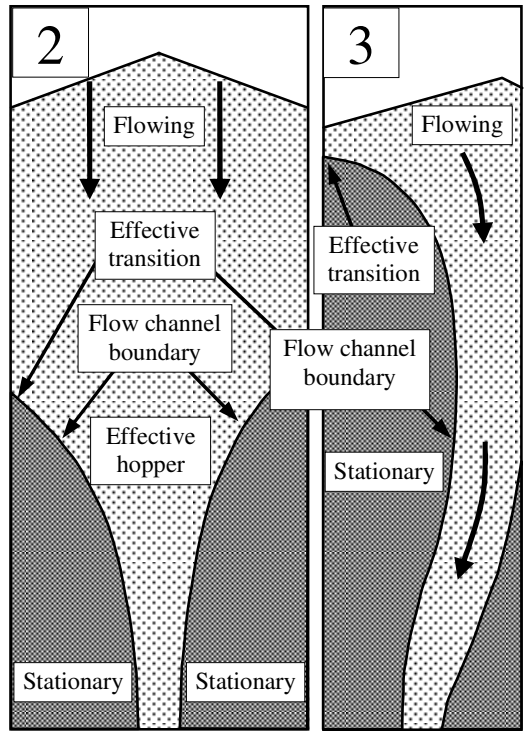

Slender silo

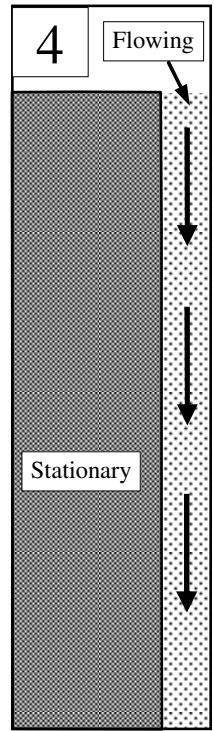

EN 1991-4 silo eccentric discharge flow model

Fig. 1 - Aspect ratio effects in different flow patterns, after EN 1991-4 (2006)

In the companion paper, it was stated that the classification of silos in the European standard EN 1991-4 (2006) on Actions on Silos and Tanks is made on the basis of their aspect ratio (height to diameter, $H / D$ ), which greatly influences the distribution of axisymmetric pressures in the silo under mass flow. The aspect ratio is also known to have an important influence on the possible patterns of mixed and pipe flow (Fig. 1), with squat silos having significantly different pipe flow regimes from slender ones (Hampe, 1987; Rotter, 2001a; EN 1991-4, 2006). The flow pattern in turn influences the pressures exerted by both the static and flowing solid components on the silo wall, 
Published in: Journal of Constructional Steel Research, 67(10), 1545-1553.

DOI: http://dx.doi.org/10.1016/j.jcsr.2011.03.027

and thus the structural behaviour of the silo. The numerous studies that tried to predict the pressures in the silo numerically based on an assumption of a particular flow pattern (e.g. Holst et al., 1999a; 1999b; Ayuga et al. 2001; Sanad et al. 2001) have above all demonstrated the great difficulty involved in doing so reliably.

\section{The EN 1991-4 eccentric discharge pressure model}

The recent European standard EN 1991-4 (2006) provides a reasonably realistic pressure distribution for silos under eccentric discharge (Fig. 2). This model assumes a parallel-sided flow channel (No. 4 in Fig. 1) with a truncated circular cross-section forming against the silo wall throughout the height of the silo, termed eccentric parallel pipe flow (Rotter, 2001a). It is prescribed for application as a separate load case on all but the very squattest of silos $(H / D>0.4)$ if the capacity is large enough or where large filling or discharge eccentricities are expected. The size of the channel is defined in terms of the ratio of the flow channel radius to full silo radius, $k_{\mathrm{c}}=r_{\mathrm{c}} / R$. EN 1991-4 recommends that three specific channel sizes be investigated, $k_{\mathrm{c}}=0.25,0.40$ and 0.60, though a National Annex may prescribe different values.

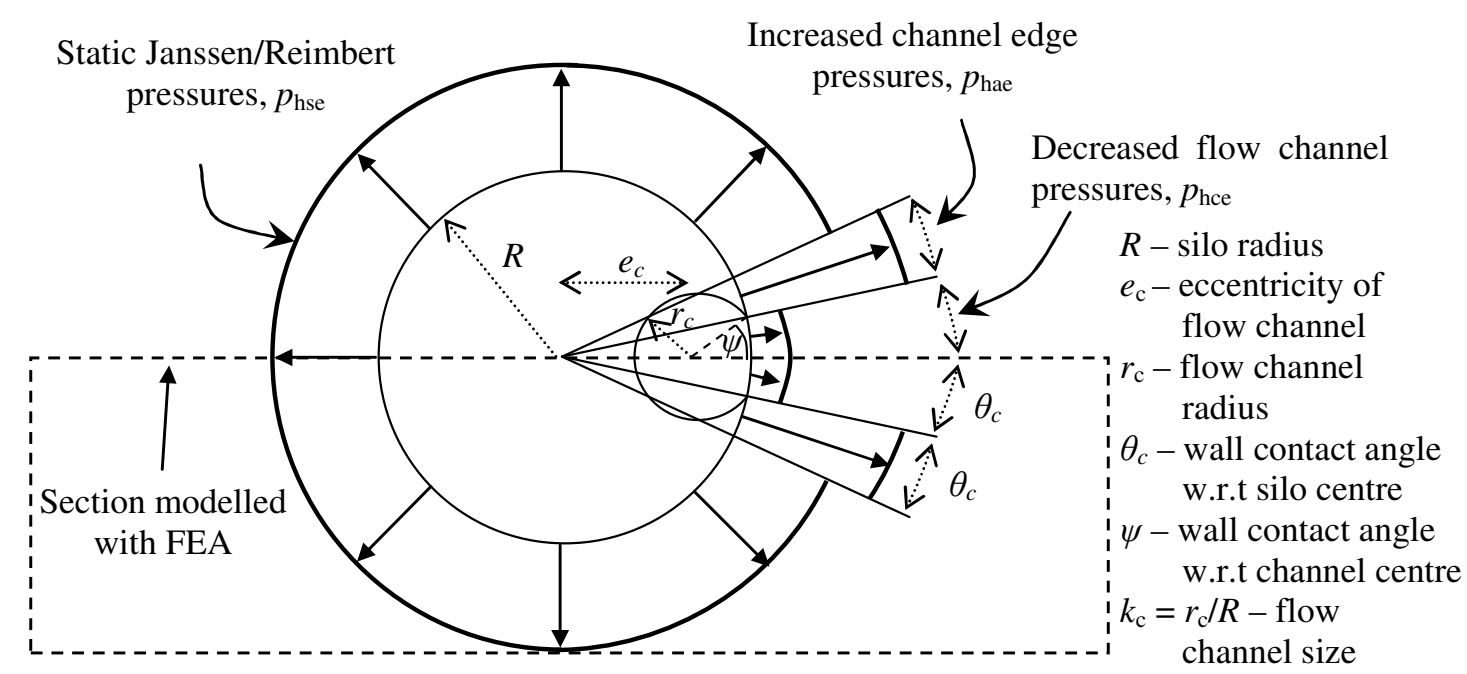

Fig. 2 - Circumferential cross-section of eccentric flow channel horizontal pressures, after EN 1991-4 (2006)

In the EN 1991-4 model, the 'flowing' solid exerts a low normal pressure on the silo wall at the centre of the flow channel $\left(p_{\text {hce }}\right)$ and a high normal pressure at the 'edges' of the flow channel $\left(p_{\text {hae }}\right)$, based on a simplified interpretation of experimental observations (Jenike, 1967; Rotter, 1986; Chrisp et al., 1988; Chen, 1996). The high 
Published in: Journal of Constructional Steel Research, 67(10), 1545-1553.

DOI: http://dx.doi.org/10.1016/j.jcsr.2011.03.027

edge pressures were chosen so that the integral of the rise in pressure is equal to that of the fall in pressure. The 'static' solid is then assumed to follow either the axisymmetric Janssen or modified Reimbert pressure distribution $\left(p_{\text {hse }}\right)$, implying that the Janssen equilibrium condition must be met irrespective of the non-uniformity of the pressures. This makes the pressures dependent on the silo aspect ratio but independent of the size of the flow channel. The EN 1991-4 model is a simplified version of the original derivation of Rotter (1986, 2001b), where the static solid pressure was instead derived rigorously by mechanics, making it a function of the flow channel size. Further, for each normal pressure component there is a corresponding frictional traction following the relation $p_{\mathrm{w}}=\mu p_{\mathrm{h}}$ (i.e. $p_{\mathrm{wce}}, p_{\text {wae }}$ and $p_{\text {wse }}$ ) where $\mu$ is the fully-developed wall friction, taken as the lower characteristic value in EN 1991-4 to emphasise the unsymmetrical nature of the normal pressure component.

As noted above, the EN 1991-4 eccentric discharge pressure pattern is based on a parallel-sided flow channel throughout the height of the silo. This is actually unlikely to occur because the channel size must reduce as it approaches the outlet, and also usually spreads out somewhat near the surface (Rotter, 2001a). Nonetheless, the channel has been defined with straight vertical sides (No. 4 in Fig. 1) in EN 1991-4 to produce a simple model for design calculations. In slender silos, the effects of this error are confined to a small part of the structure, but in squatter silos this error covers a significant part of the silo and results in quite unrealistic imposed pressure patterns, especially when combined with the modified Reimbert distribution for static pressures $\left(p_{\text {hse }}\right)$.

The structural response of silo structures of different geometry to this pressure pattern remains largely unknown because the pattern was only recently codified and very few experiments have ever been conducted to explore this failure mode. It is probable that the computational prediction of the structural behaviour depends on the geometry of the silo, the size and position of the flow channel, the assumed material properties of the granular solid and the type of computational analysis. The present study is an investigation of the most influential of these factors: the silo aspect ratio. 
Published in: Journal of Constructional Steel Research, 67(10), 1545-1553.

DOI: http://dx.doi.org/10.1016/j.jcsr.2011.03.027

The first known studies of the EN 1991-4 eccentric discharge model are those of Sadowski \& Rotter (2010; 2011), who performed a full set of computational analyses according to EN 1993-1-6 (2007): LA, LBA, MNA, GNA, GMNA, GNIA and GMNIA, the definitions of which may be found in the companion paper. They studied only metal silos with slender aspect ratios $(H / D>2)$ with stepped walls and always assuming the largest recommended flow channel size of $k_{\mathrm{c}}=r_{\mathrm{c}} / R=0.60$. They showed that the mechanics of behaviour of the shell under this load pattern is highly complex and that the predicted buckling modes correspond well to those observable in the field. Rather surprisingly, a slender silo that is subject to the EN 1991-4 eccentric discharge pressures was found to exhibit a higher buckling strength when analysed with a geometrically nonlinear analysis (GNA) than with a linear bifurcation analysis (LBA). On average, the lowest GNA load proportionality factor was found to be approximately $44 \%$ higher than the lowest LBA linear buckling eigenvalue. However, these explorations were clearly very limited in that they studied only a single flow channel size and two aspect ratios in the slender range which, as will be shown in this paper, are far from representing the full range of possible behaviours under this particularly complex load condition.

\section{Scope of the present study}

The companion paper introduced the design of five example silos with varying aspect ratios in the range $0.65 \leq H / D \leq 5.20$, linked by a common storage capacity of 510 $\mathrm{m}^{3}$. The silos were assigned identification acronyms based on their slenderness category according to EN 1991-4 (2006): 'squat' Silo Q $(H / D=0.65)$, 'intermediate' Silo I $(H / D=1.47)$, 'boundary' Silo B $(H / D=2.06)$, 'slender' Silo $\mathrm{S}(H / D=3.00)$ and 'very slender' Silo VS $(H / D=5.20)$. The reader may consult the companion paper to find full details of the structural design, modelling procedure and subsequent analysis, which are employed again in the present study of eccentric discharge.

The aspect ratios of all but the squattest of the example silos were chosen to be in a range where an eccentric pipe flow pattern might be physically possible (Nos $3 \& 4$ in Fig. 1). Eccentric pipe flow is known to occur in slender silos storing densely packed or slightly cohesive solids (Rotter, 2001a; Zhong et al., 2001), but it is no longer credible in squat silos which exhibit fully internal and mixed flow patterns where the 
Published in: Journal of Constructional Steel Research, 67(10), 1545-1553.

DOI: http://dx.doi.org/10.1016/j.jcsr.2011.03.027

channel spreads progressively outwards from the outlet (Nos $1 \& 2$ in Fig. 1). Consequently, the very squat Silo Q $(H / D=0.65)$ was omitted from the present study. Nonetheless, it will be shown here that the structural behaviour of a silo of low aspect ratio under the EN 1991-4 eccentric pipe flow model is significantly different from that of a slender silo. This issue was not considered in the authors' earlier work (Sadowski \& Rotter, 2010; 2011) and was not discussed by the code drafting committee for EN 1991-4.

The geometry of the EN 1991-4 eccentric discharge pressure model is shown in Fig. 2. The flow channel wall contact angles $\theta_{\mathrm{c}}$ and $\psi\left(\right.$ Eqs 1 and 2), the area ratio $A_{\mathrm{c}} / A_{\text {tot }}$ (Eq. 3) and the dimensionless eccentricity $e_{\mathrm{c}} / R$ (Eq. 4) are each a function of the assumed dimensionless size of the channel $k_{\mathrm{c}}=r_{\mathrm{c}} / R$ and the friction properties of the solid and the silo wall only. The general definition of the flow channel geometry is thus independent of the aspect ratio of the silo.

$$
\begin{aligned}
& \theta_{c}=\cos ^{-1}\left(\frac{1}{2}\left\{\frac{R}{e_{c}}\left(1-k_{c}^{2}\right)+\frac{e_{c}}{R}\right\}\right) \\
& \psi=\sin ^{-1}\left(\frac{1}{k_{c}} \sin \theta_{c}\right)
\end{aligned}
$$

The angle $\psi$ approaches $90^{\circ}$ when the wall is very smooth (Rotter, 1986).

$$
\begin{aligned}
& A_{c} / A_{\text {tot }}=\frac{1}{\pi}\left\{(\pi-\psi) k_{c}^{2}+\theta_{c}-k_{c} \sin \left(\psi-\theta_{c}\right)\right\} \\
& e_{c} / R=\left\{\frac{\mu_{\text {lower }}}{\tan \phi_{i, \text { upper }}}\left(1-k_{c}\right)+\left(1-\frac{\mu_{\text {lower }}}{\tan \phi_{i, \text { upper }}}\right) \sqrt{1-k_{c}}\right\}
\end{aligned}
$$

where $k_{c}=\frac{r_{c}}{R}$.

In the present study, Silos VS, S, I and B were analysed under each of the three flow channel sizes recommended by EN 1991-4: $k_{\mathrm{c}}=r_{\mathrm{c}} / R=0.25,0.40$ and 0.60 . The values of the dimensionless geometric parameters are summarised in Table 1 and Fig. 3 , assuming the same granular solid properties as those initially used in design. For the smallest flow channel $\left(k_{\mathrm{c}}=0.25\right)$, the region of low pressure covers less than $6 \%$ of the wall perimeter, while for the largest flow channel $\left(k_{\mathrm{c}}=0.60\right)$ it rises only to 
Published in: Journal of Constructional Steel Research, 67(10), 1545-1553.

DOI: http://dx.doi.org/10.1016/j.jcsr.2011.03.027

$16 \%$. Thus all three recommended channel sizes have a relatively small wall contact perimeter.

Table 1 - Summary of flow channel properties for any of the four design silos

\begin{tabular}{|c|c|c|c|c|}
\hline$k_{\mathrm{c}}=r_{\mathrm{c}} / R$ & Dimensionless flow channel size & 0.25 & 0.40 & 0.60 \\
\hline$e_{\mathrm{c}} / R$ & Dimensionless eccentricity & 0.808 & 0.688 & 0.517 \\
\hline$\theta_{\mathrm{c}} / \pi(\%)$ & Percentage perimeter contact & 5.7 & 9.7 & 16.0 \\
\hline$A_{\mathrm{c}} / A_{\mathrm{tot}}(\%)$ & Percentage channel area & 5.8 & 14.8 & 33.4 \\
\hline
\end{tabular}

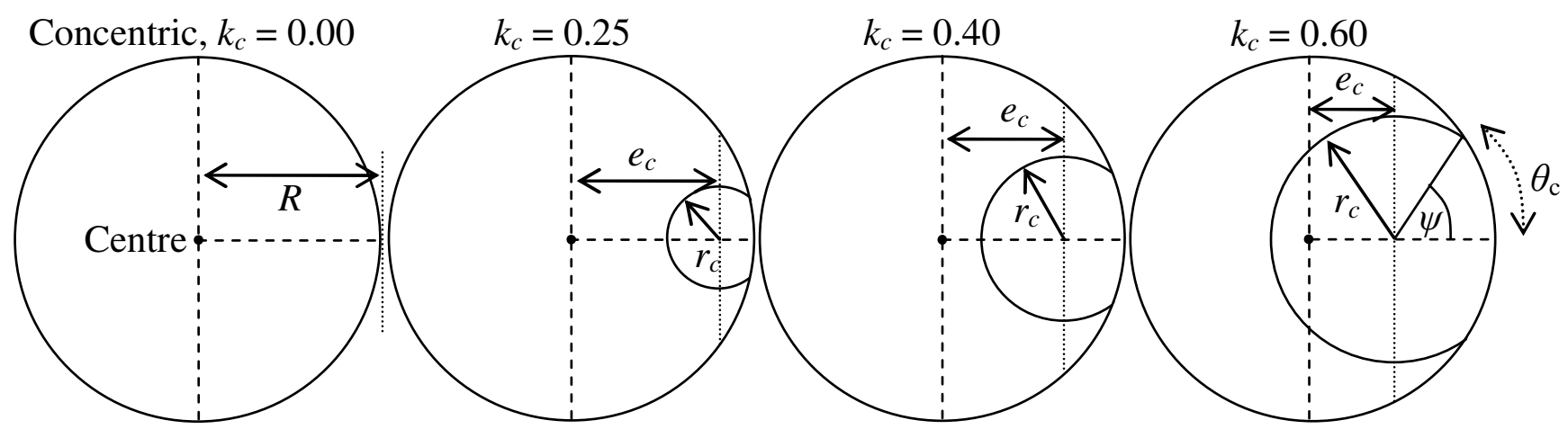

Fig. 3 - Comparison of the geometry of four different EN 1991-4 discharge conditions (independent of aspect ratio), drawn to scale

The full set of EN 1993-1-6 global numerical analysis calculations were performed with ABAQUS (2009) for each channel size on every silo (LA, LBA, MNA, GNA, GMNA, GNIA \& GMNIA). The modelling procedure, material properties, imperfection form and amplitudes were taken to be same as for the concentric discharge calculations presented in the companion paper (Type A axisymmetric weld depression of Rotter \& Teng, 1989). A single axis of symmetry in the EN 1991-4 eccentric discharge model permitted half of the silo to be modelled. The modelling of a conical roof at the top boundary (inclined at $15^{\circ}$ to the horizontal) was required to realistically restrict out of round displacements at this location which develop due to the unsymmetrical pattern of loading. Such displacements would adversely affect the stress patterns in the silo (Calladine, 1983).

\section{Stress patterns under eccentric discharge}

The only known previous computational studies of stresses in metal silos under the eccentric discharge pressure model of EN 1991-4 and its precursors (Rotter, 1986; 
Published in: Journal of Constructional Steel Research, 67(10), 1545-1553.

DOI: http://dx.doi.org/10.1016/j.jcsr.2011.03.027

2001b; Sadowski \& Rotter, 2010; 2011) explored the resulting characteristic distribution of axial membrane stresses and identified two critical locations for buckling failure (Fig. 4). In the first location, high compressive axial membrane stresses develop in the silo wall adjacent to the centre of the flow channel at approximately midheight, possibly causing predominantly elastic local buckling. In the second location, very high axial compression develops at the base of the silo adjacent to the edge of the flow channel, potentially causing a local plastic buckle.

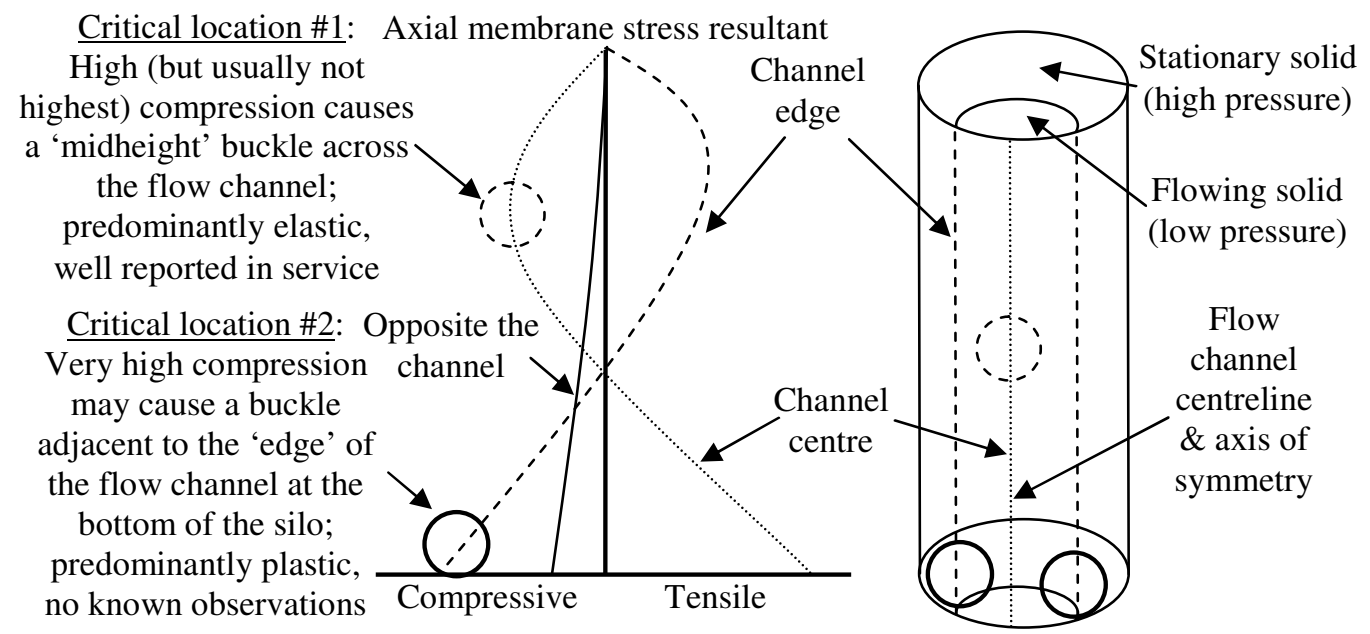

Fig. 4 - Illustration of the critical locations under eccentric pipe flow in slender silos
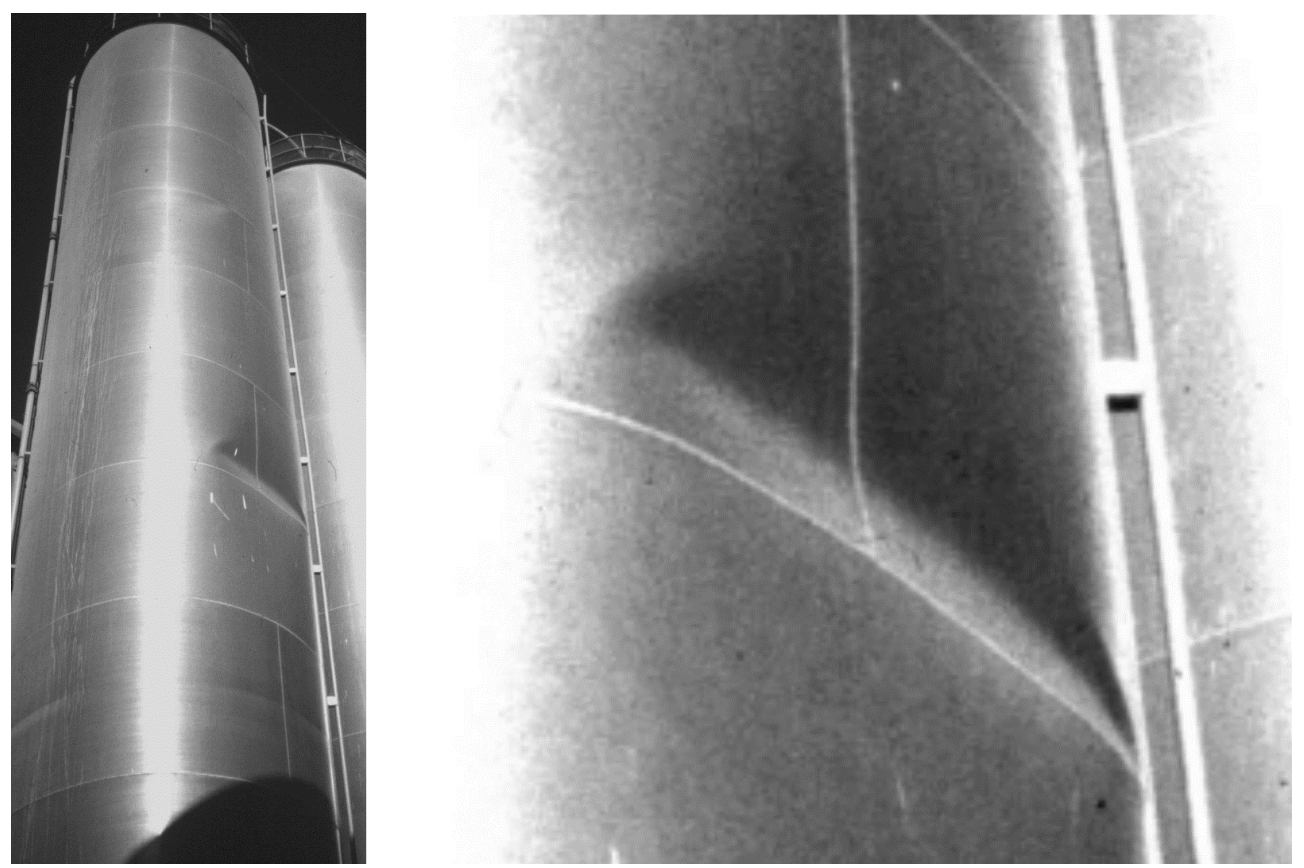

Fig. 5 - Example of an observed elastic 'midheight channel' buckle in a slender silo in service caused by eccentric pipe flow (photo courtesy of J.M. Rotter) 
Published in: Journal of Constructional Steel Research, 67(10), 1545-1553.

DOI: http://dx.doi.org/10.1016/j.jcsr.2011.03.027

In slender silos, the axial compression at the base is usually much greater than that near midheight, but buckling at the base attributable to eccentric discharge is unknown as a field observation. By contrast, the midheight buckle has been widely reported (e.g. Fig. 5) and often precipitates catastrophic buckling failure. The reasons for this are explored in what follows.

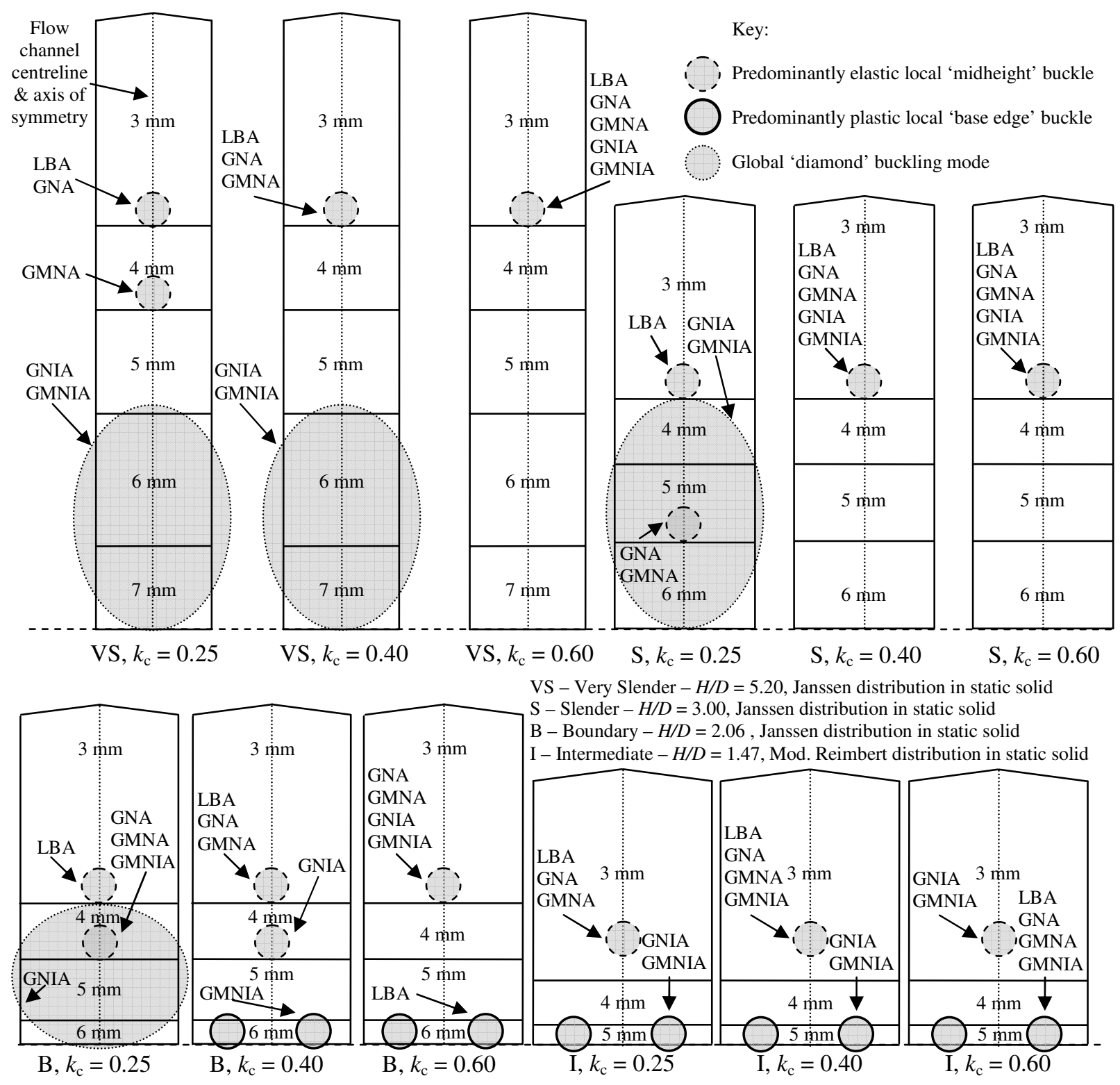

Fig. 6 - Summary schematic of failure mode locations on the four design silos analysed under eccentric discharge, drawn to scale 
Published in: Journal of Constructional Steel Research, 67(10), 1545-1553.

DOI: http://dx.doi.org/10.1016/j.jcsr.2011.03.027

\section{Predicted failure modes}

Four silo designs under three flow channel sizes were analysed using seven different analysis types, resulting in 84 different sets of unsymmetrical stress patterns, each with six stress resultants as well as buckling modes and failure mechanisms. The volume of results, and their complexity, makes it difficult to provide a brief description with adequate explanation of the mechanics and the phenomena. A general schematic summary was therefore prepared (Fig. 6) and each failure mode classified as a 'midheight' buckling mode (e.g. Fig. 7a), a 'base edge' buckling mode (e.g. Fig. 7b) or a 'diamond' buckling mode (e.g. Fig. 7c). A plastic collapse mechanism caused by circumferential bending (e.g. Fig. 7d) was found to be similar in location and form for every MNA analysis, regardless of silo or channel size, and is thus not marked in Fig. 6. Lastly, a peculiar result was obtained in the GMNIA analyses of Silo I for the two larger channel sizes $k_{\mathrm{c}}=0.40$ and 0.60 (e.g. Fig. 7e), where both buckling locations associated with eccentric discharge (Fig. 4) became critical at the same load factor.

The 'midheight' buckling mode prediction appears to be ubiquitous, regardless of the aspect ratio of channel size. The 'base edge' buckling mode was not obtained in any analysis of the two most slender Silos VS and S, though it was predicted in the squatter Silos B and I. A realistic silo with a stepped wall construction has a thinner wall near midheight and thus lower buckling resistance than at the base. This partly explains why the 'midheight' buckle is widely observed in field observations of eccentric discharge failures.

The predominantly plastic 'base edge' buckling mode is associated with a high channel edge pressure ( $p_{\text {hae }}$, Fig. 2) coupled with high axial stress. This plastic stability mode corresponds to the elephant's foot failure described by Rotter (1990, 2006) and covered by the provisions of EN 1993-1-6 (2007). However, this high local pressure is most unlikely to occur at this location as the flow channel cannot have the same geometry near the base (Chen et al., 2007), and the EN 1991-4 (2006) pressure model is clearly in error there (Sadowski, 2010). Moreover, the static solid near the base has a high stiffness and is known to significantly enhance the buckling strength (Rotter \& Zhang, 1990; Knödel et al., 1995). As this stiffness is omitted from the 
Published in: Journal of Constructional Steel Research, 67(10), 1545-1553.

DOI: http://dx.doi.org/10.1016/j.jcsr.2011.03.027

present study, the predictions of this failure mode may be safely ignored. Further, it may be advisable to restrict the application of the EN 1991-4 eccentric discharge pressure mode, in its current form, to the analysis of slender silos $(H / D \geq 2.0)$. The authors believe that a different model for eccentric discharge pressures should be devised for squatter silos, based on a flow channel of varying geometry (Sadowski, 2010).

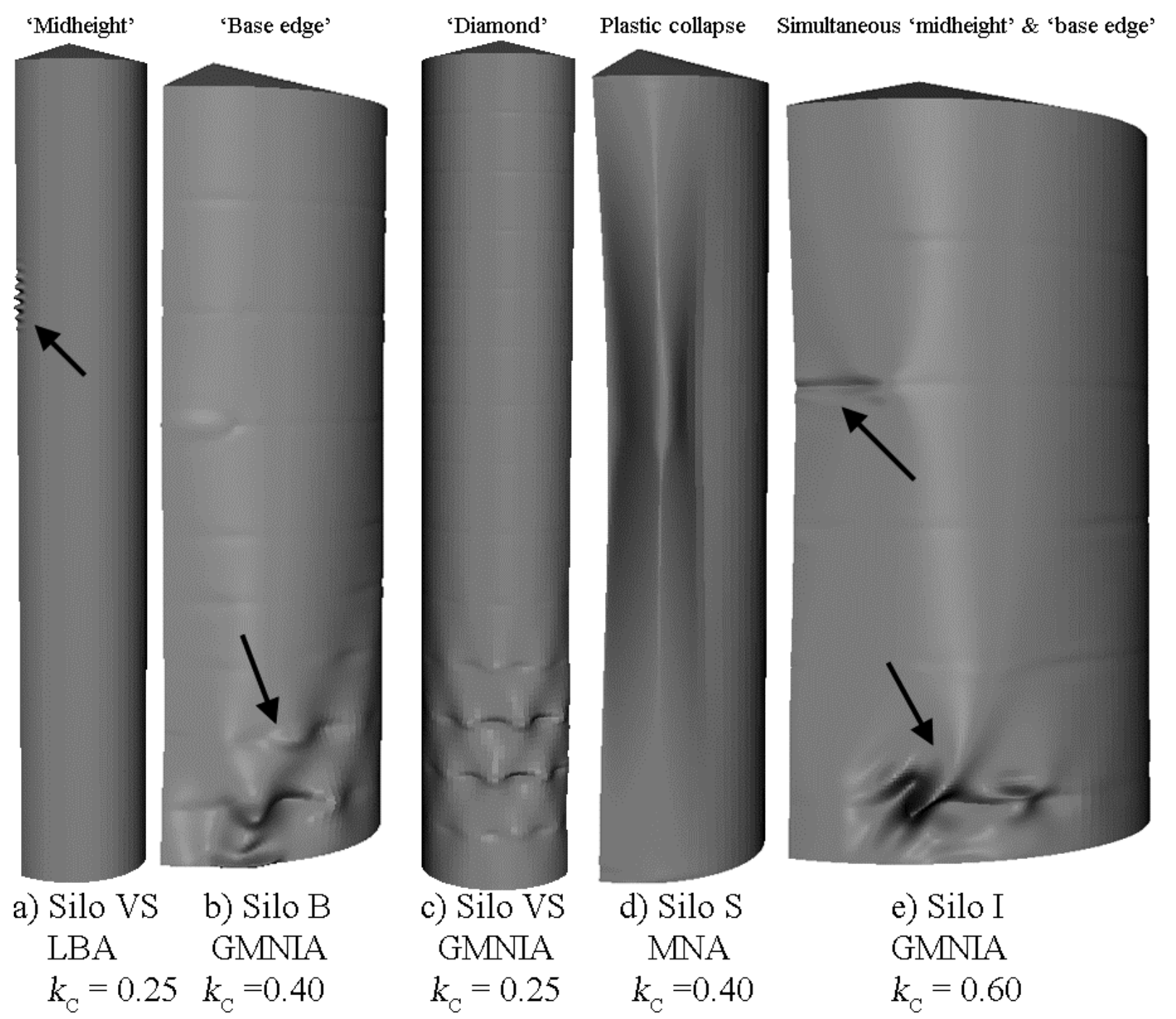

Fig. 7 - Examples of predicted failure modes, not shown to scale

\section{The effect of geometric nonlinearity}

The 'midheight' buckling mode has been referred to extensively in this paper and was already identified by Rotter (1986, 2001b) and Sadowski \& Rotter (2010; 2011). However, the commonest location for this buckle is just above an increase in wall thickness. It is often located in the thinnest strake with the lowest buckling resistance. 
Published in: Journal of Constructional Steel Research, 67(10), 1545-1553.

DOI: http://dx.doi.org/10.1016/j.jcsr.2011.03.027

For the three most slender Silos VS, S and B, the linear LBA 'midheight' buckle was always predicted to occur at the base of the thinnest strake regardless of flow channel size. By contrast, with the smallest channel size of $k_{\mathrm{c}}=0.25$, a nonlinear GNA analysis of the same three silos predicts that this buckling mode occurs instead in one of the lower thicker strakes. Thus the characteristic distribution of axial membrane stresses responsible for the 'midheight' peak (Fig. 4) has not yet developed for such a small channel.

The axial membrane stress resultant distributions through the centre of the channel in Silo $\mathrm{S}$ at buckling are shown in Fig. 8. The LA analyses consistently predict an approximately midheight peak, regardless of channel size. By contrast, as the channel size grows, the GNA analyses exhibit a progressive growth and displacement of the peak compressive membrane stress resultant, and a strong peak is only established for channel sizes larger than $k_{\mathrm{c}}=0.40$. The axial stresses are higher in the thinner strakes and the buckling resistance is lower: thus the buckles should always occur in the thinner strakes. However, this is not the case for $k_{\mathrm{c}}=0.25$ and the critical buckle is found at the base of the $5 \mathrm{~mm}$ strake (Fig. 6), corresponding to a slight compressive peak visible in Fig. 8 at a depth of approximately $z / H=0.77$.

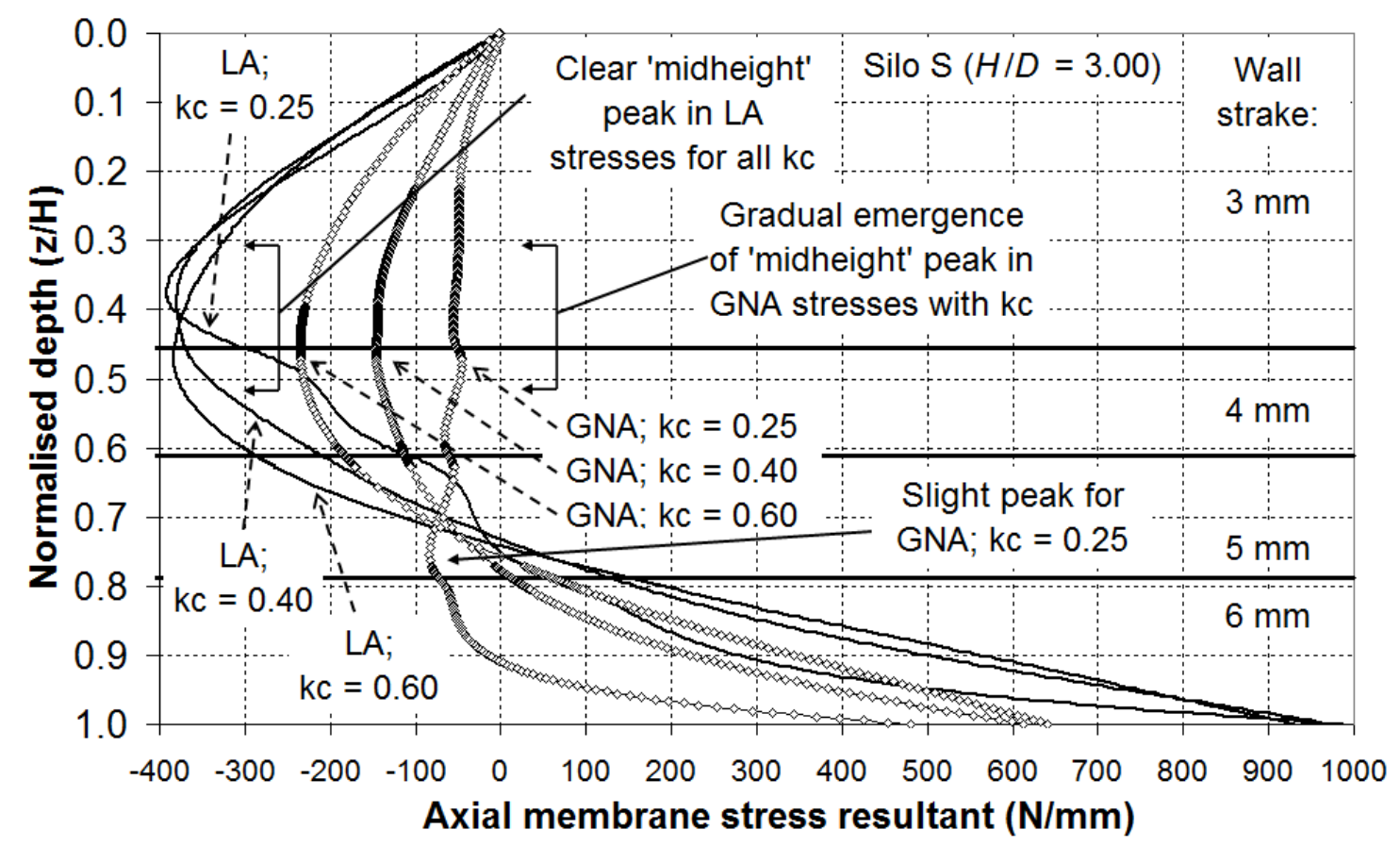

Fig. 8 - Silo S: Distribution of LA and GNA axial membrane stress resultants at buckling through the centre of the channel 
Published in: Journal of Constructional Steel Research, 67(10), 1545-1553.

DOI: http://dx.doi.org/10.1016/j.jcsr.2011.03.027

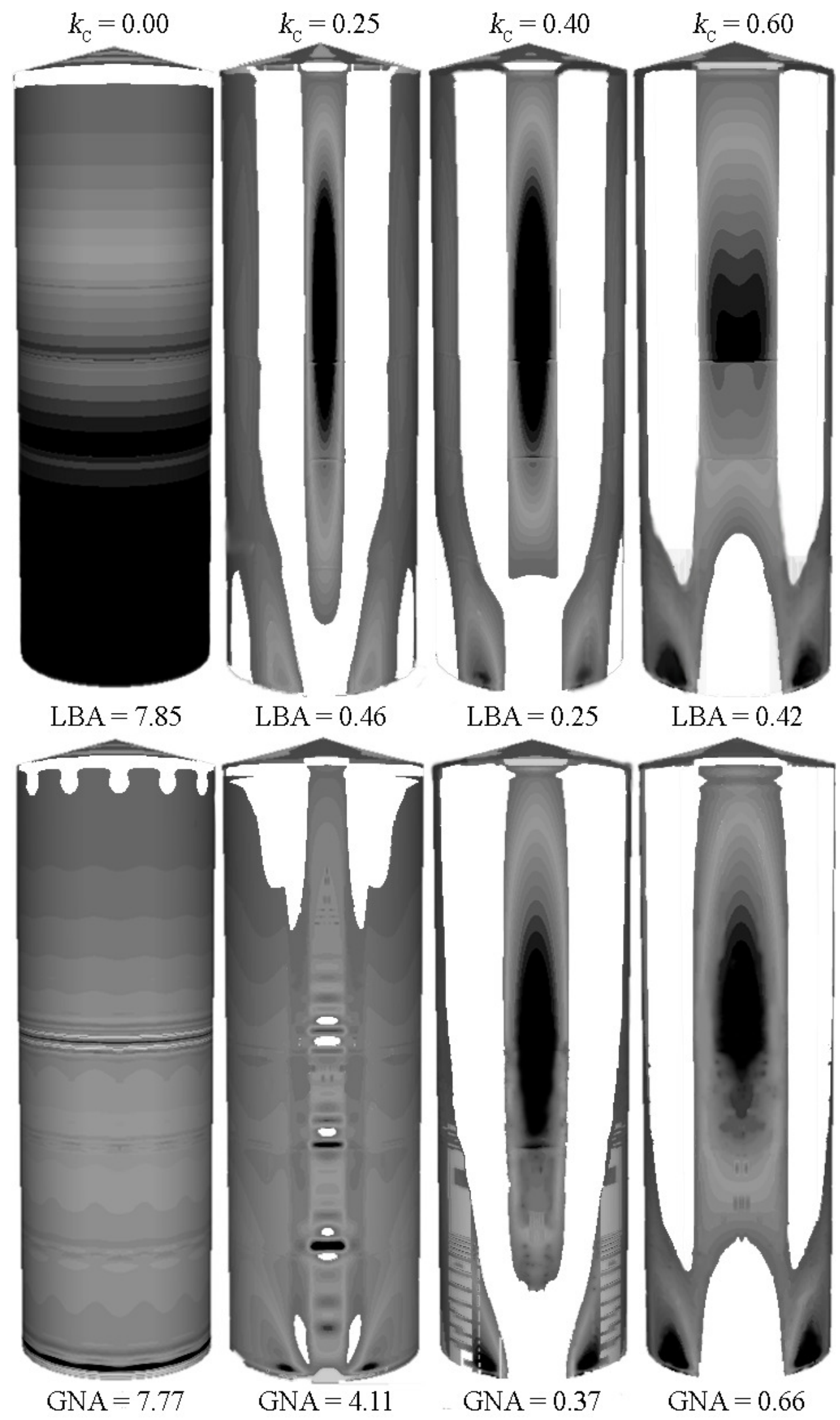

Fig. 9 - Silo S: Contour plots of LA and GNA compressive axial stresses at buckling, with corresponding load factors (darkest regions shown high compression, solid white regions show tension) 
Published in: Journal of Constructional Steel Research, 67(10), 1545-1553.

DOI: http://dx.doi.org/10.1016/j.jcsr.2011.03.027

The difference between the LA and GNA axial stress distributions for Silo $\mathrm{S}$ is illustrated in Fig. 9, which shows a global greyscale contour plot of the compressive axial stresses at buckling for the four channel sizes, with corresponding LBA and GNA load factors. This figure has been altered to darken regions of highest axial compression and to remove graphical artefacts caused by the ABAQUS software, though some still remain. The characteristic pattern of axial stresses which cause the 'midheight' buckle (Fig. 4) can be seen in all the LBA analyses (except $k_{\mathrm{c}}=0.00$ ), but only for the large channel sizes $\left(k_{\mathrm{c}}=0.40\right.$ and 0.60$)$ in the GNA analyses. This pattern is furthermore associated with a massive fall in the corresponding LBA load factor from the concentric value of $7.85\left(k_{\mathrm{c}}=0.00\right)$ to less than a half for $k_{\mathrm{c}} \geq 0.25$. By contrast, the GNA analysis for the small channel $\left(k_{\mathrm{c}}=0.25\right)$ produces a global stress state at buckling that is only slightly different from that at $k_{\mathrm{c}}=0.00$. There is a local perturbation of the stress state in the vicinity of the flow channel, but the GNA load factor is only reduced from 7.77 to 4.11 . A significantly larger channel size of $k_{\mathrm{c}}=$ 0.40 is required to produce the characteristic stress pattern that causes the 'midheight' buckle and to cause a drop in the GNA load factor to below unity. It is, perhaps, unexpected that the GNA factor is still approximately $60 \%$ higher than the LBA factor when both analyses predict a 'midheight' buckle.

Similar observations may be made for Silos VS and B. Thus, geometric nonlinearity has a powerful beneficial effect on the buckling strength assessment of a slender silo under eccentric discharge, causing the silo to be more resistant to asymmetries in the applied load patterns. It appears that buckling strength predictions of the 'midheight' buckle always give particularly low load factors, making this buckling mode an excellent candidate to use in developing a conservative design procedure for this particularly problematic load condition. It may however be prudent to restrict the recommended sizes of flow channels in the EN 1991-4 standard to mid-size ones or larger (e.g. $k_{\mathrm{c}} \geq 0.40$ ) in order to ensure that the 'midheight' buckling mode is the outcome. Significantly more research is needed to explore the mechanics of the nonlinear behaviour of cylindrical shells under unsymmetrical strip-like load patterns. 
Published in: Journal of Constructional Steel Research, 67(10), 1545-1553.

DOI: http://dx.doi.org/10.1016/j.jcsr.2011.03.027

\section{Load proportionality factors}

The full set of load proportionality factors is summarised in Fig. 10. Each entry has been normalised by the LBA factor (listed in the figure) for the corresponding silo and flow channel size. Entries with a black diamond above them relate to a kink on the load-displacement path (e.g. Fig. 11) in the absence of a clear limit point or bifurcation, as stated in EN 1993-1-6 (2007). A number of important trends may be identified on this figure, as follows.

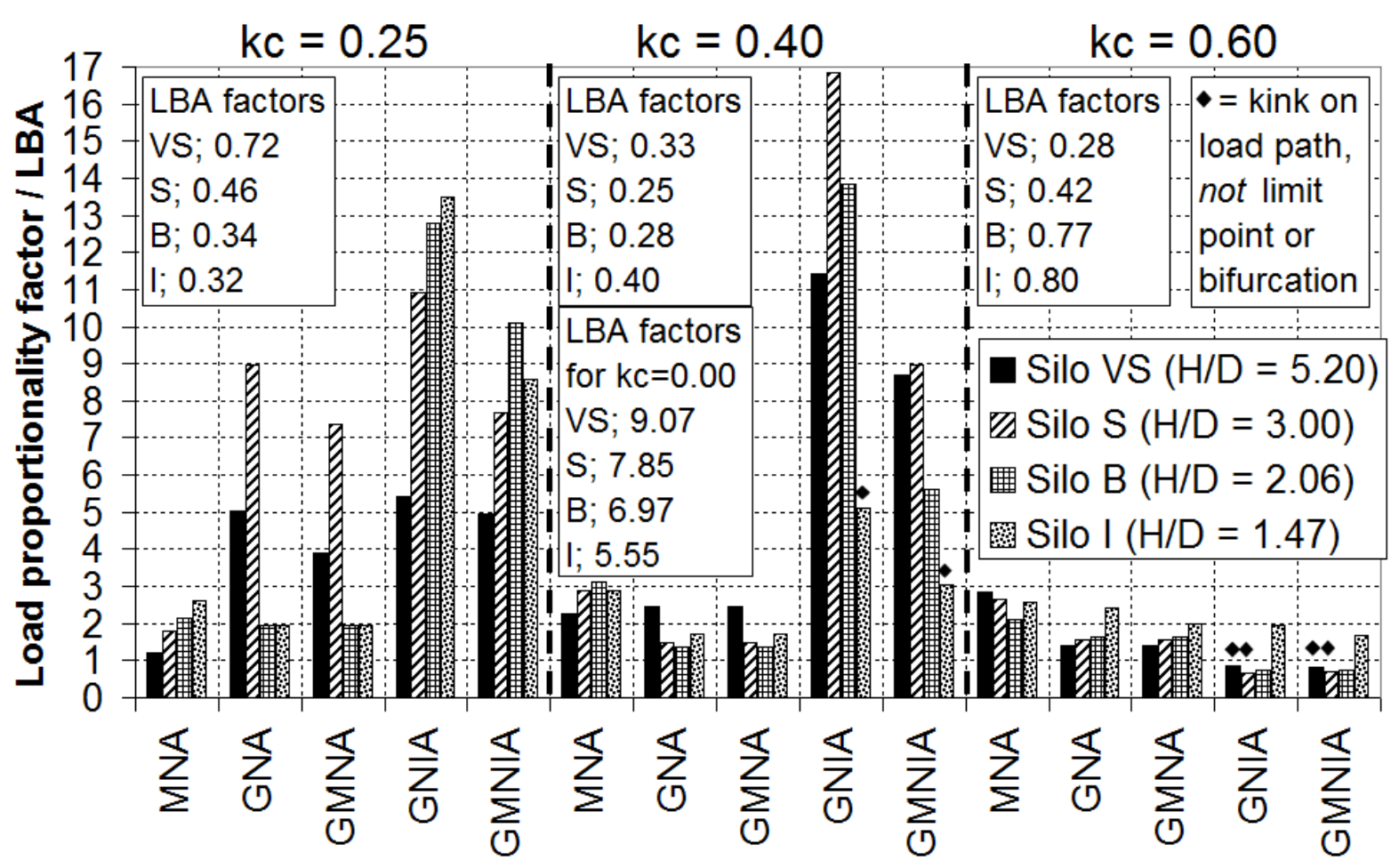

Fig. 10 - Summary of computed load proportionality factors normalised by the respective LBA load factor for each separate silo and flow channel

Firstly, each of the LBA factors under eccentric discharge falls far below unity and is only a fraction of the predicted LBA factor under concentric discharge (see companion paper). This represents a massive loss in buckling strength even for the smallest flow channel size of $k_{\mathrm{c}}=0.25$, despite the small perimeter of the region of low pressure zone (less than $6 \%$ of the wall parameter: Table 1). One of the main conclusions of the companion paper was the very significant conservatism of the EN 1993-1-6 structural design rules for metal silos under axisymmetric loading. Under the eccentric discharge pressure pattern, all conservatism has been wiped out. 
Published in: Journal of Constructional Steel Research, 67(10), 1545-1553.

DOI: http://dx.doi.org/10.1016/j.jcsr.2011.03.027

Secondly, the increase in buckling strength from LBA to GNA may be as high as a factor of 9, showing that geometric nonlinearity provides an important strengthening effect. This strength gain is highest for the smallest channel and the two most slender Silos VS and S. For the larger channels and the squatter Silos B and I, the strength gain is more modest, though still significant (around a factor of 2).

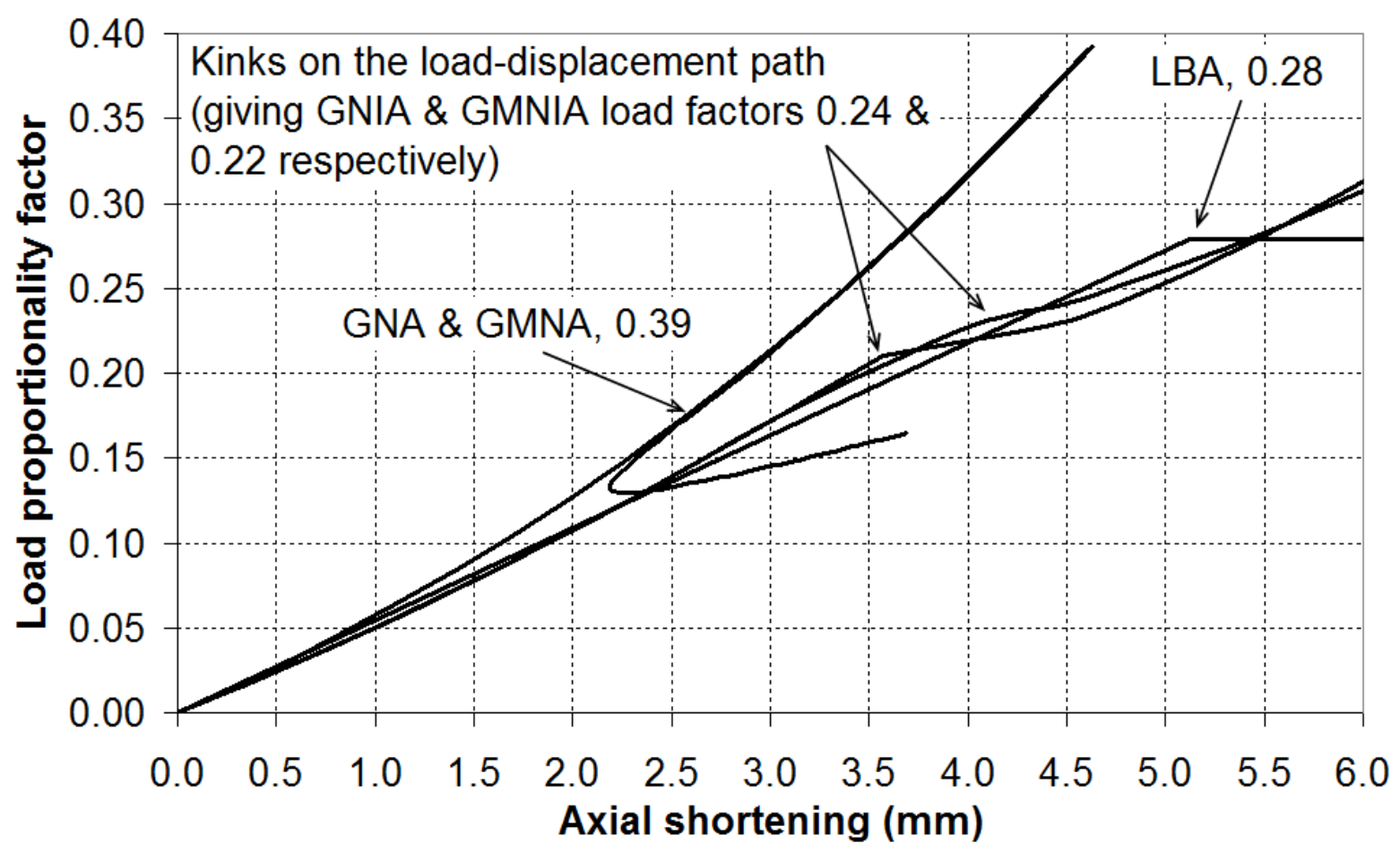

Fig. 11 - Silo VS: Load-axial deflection paths under eccentric discharge with $k_{\mathrm{c}}=$ 0.60 (the node being followed is at the top of the silo cylinder at the centre of the flow channel)

Lastly, the introduction of axisymmetric weld depressions, combined with geometric nonlinearity, was found to increase the buckling load factor further from GNA to GNIA. This effect is especially strong for the smallest and medium-sized channels, where in one case the GNIA load factor is 17 times the perfect shell GNA value. Furthermore, the load-deflection path of the imperfect slender silo under eccentric discharge shows a kink in the curve at a certain load factor, with no reported negative eigenvalues in the tangent stiffness matrix (Fig. 11). At this load factor, the silo undergoes a smooth transition from pre- to post-buckling states as a direct result of a high imperfection amplitude which eliminates the bifurcation point (Yamaki, 1984). 
Published in: Journal of Constructional Steel Research, 67(10), 1545-1553.

DOI: http://dx.doi.org/10.1016/j.jcsr.2011.03.027

This behaviour occurs for a wide range of aspect ratios where the flow channel is quite large. It shows that the axisymmetric weld depression is an inappropriate choice of imperfection for the eccentric discharge load condition.

\section{The effect of axisymmetric weld imperfections}

In the companion paper on concentric discharge, it was shown that the Type A axisymmetric weld depression of Rotter and Teng (1989) leads to a significant loss of linear stiffness of the equilibrium path and a high reduction in the buckling load factor for each of the example silos considered here. For the Very Slender Silo VS, for example, the load factor drops from 9.07 (LBA) to 4.40 (GNIA), while the introduction of material plasticity reduces this load factor further to 3.77 (GMNIA). Furthermore, the failure mode for the imperfect Silo VS was predicted to be a global 'diamond' buckling mode, showing signs of interactions between adjacent weld depressions (e.g. Fig 7c).

In this paper, it has been shown that the 'midheight' buckling mode is a ubiquitous prediction for the three perfect slender Silos VS, S and B $(H / D \geq 2.0)$ under eccentric discharge (Figs $4 \& 5$ ), and is associated with very low LBA and GNA load factors. However, GNIA analyses of the same silos predicted instead the 'diamond' buckling mode for the smallest flow channels, $k_{\mathrm{c}}=0.25$ and 0.40 (Figs $6 \& 12$ ). Each instance of the 'diamond' buckling mode was additionally found to be associated with high GNIA load factors that are significantly above the corresponding GNA factor, but only slightly below the corresponding GNIA factor under concentric discharge. Thus the finding that the imperfect shell turns out to be stronger than the perfect shell runs counter to expectations and contradicts the conceptual basis of EN 1993-1-6 where a geometric imperfection is intended to have a detrimental effect on the structure. The reasons for this are explained in what follows. 
Published in: Journal of Constructional Steel Research, 67(10), 1545-1553.

DOI: http://dx.doi.org/10.1016/j.jcsr.2011.03.027

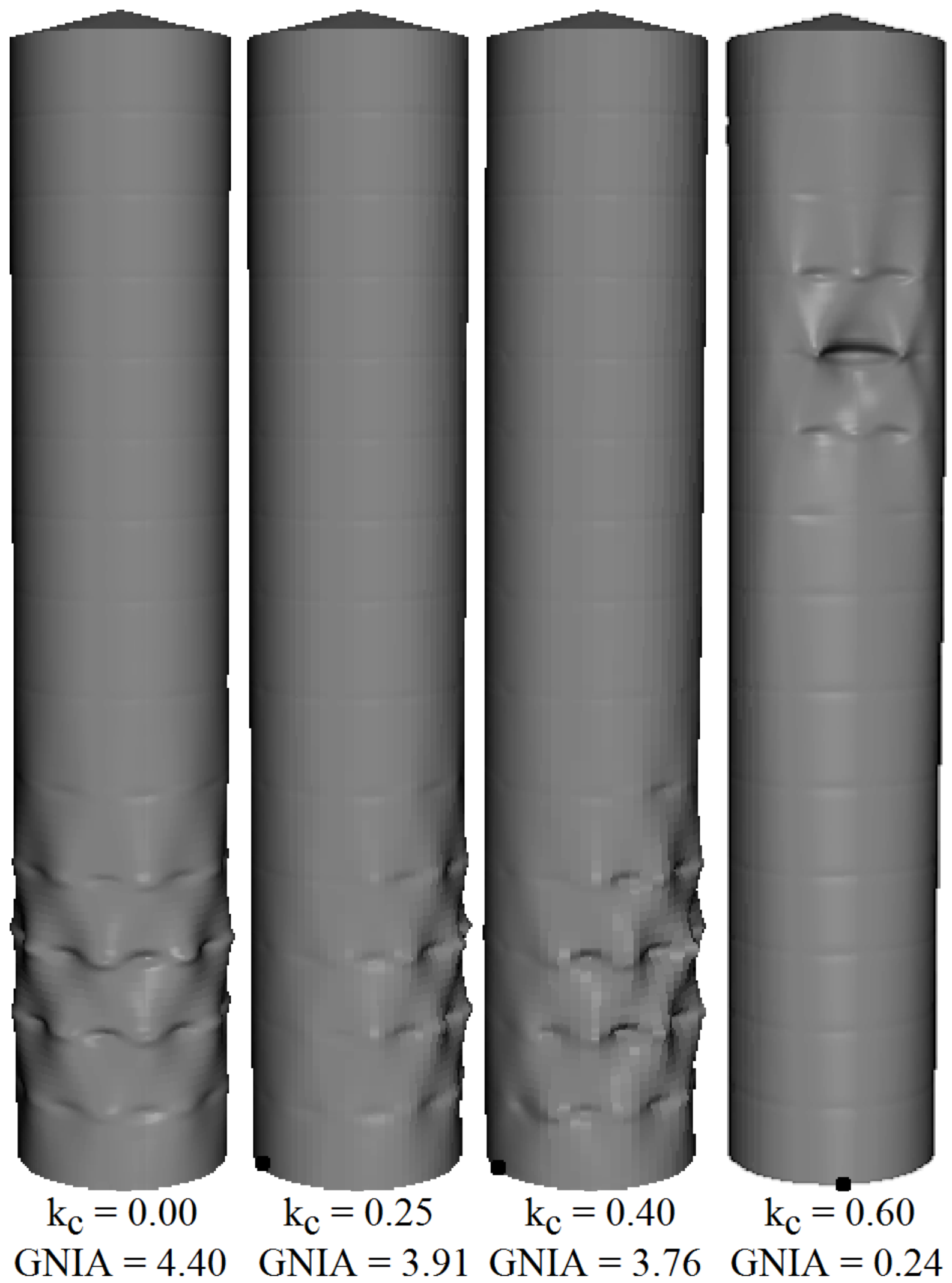

Fig. 12 - GNIA incremental buckling modes and load factors for Silo VS (black dots represent the centre of the flow channel) 
Published in: Journal of Constructional Steel Research, 67(10), 1545-1553.

DOI: http://dx.doi.org/10.1016/j.jcsr.2011.03.027

The EN 1991-4 eccentric discharge pressure distribution causes significant inward circumferential bending of the wall due to the large magnitude of the pressure drop (Fig. 2). Though the axisymmetric weld depression significantly reduces the linear stiffness response of a silo under concentric discharge, under eccentric discharge it increases the second moment of area of the shell in circumferential bending, enhanced by an inward displacement of the effective section centroid (Fig. 13). The increased second moment of area for circumferential bending makes the shell much more resistant to inward bending action in the flow channel region. When combined with the additional stiffening effect of geometric nonlinearity, the imperfect shell is found to resist the eccentric discharge pressures very well. This causes the 'midheight' buckle and its associated very low load factor to be predicted only when the silo is subjected to the largest recommended flow channel size, $k_{\mathrm{c}}=0.60$. However, even this is not a fully satisfactory result, since the GNIA load factors and incremental buckling modes for $k_{\mathrm{c}}=0.60$ refer to a kink in the load-deflection path (e.g. Fig. 11), rather than a clearly-defined bifurcation or limit point. The same is also true for GMNIA analyses.

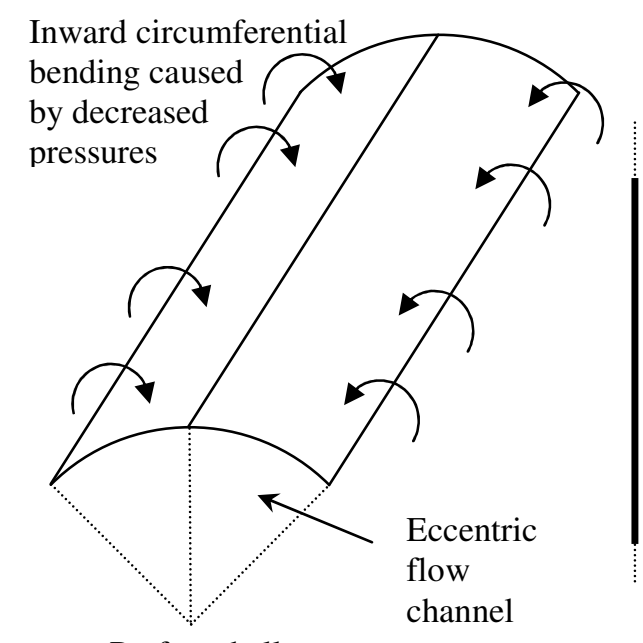

Perfect shell

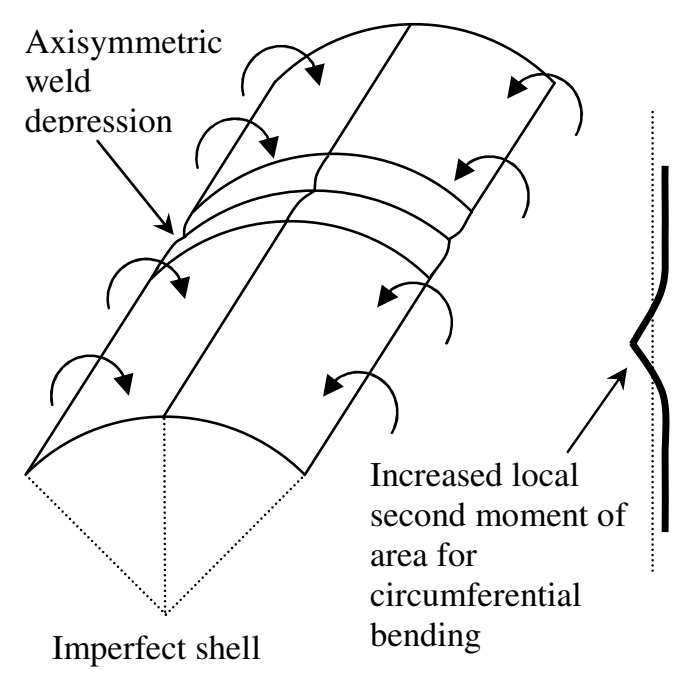

Imperfect shell

Fig. 13 - Comparison of the behaviour of perfect and imperfect shells with axisymmetric weld imperfections

The evaluation of the value of $k_{\mathrm{c}}$ at which the effect of the axisymmetric weld depression changes from being beneficial to detrimental has not yet been determined. However, the present findings strongly suggest that the axisymmetric weld is not a satisfactory imperfection form for this load condition. More research is required to 
Published in: Journal of Constructional Steel Research, 67(10), 1545-1553.

DOI: http://dx.doi.org/10.1016/j.jcsr.2011.03.027

determine a realistic and deleterious imperfection form for slender silos under the EN 1991-4 eccentric discharge pressures.

\section{The effect of material plasticity}

In the companion paper, it was shown that the analysis of a silo under concentric discharge results in a stress state corresponding to uniform axial compression and internal pressure. Plasticity was thus found to be widespread and interacting closely with the buckling mode, so that all GMNA and many GMNIA analyses predicted the elastic-plastic elephant's foot buckling mode.

The effect of material plasticity appears to be very limited in eccentric discharge predictions, where the buckling phenomenon has been shown to be predominantly elastic and caused by locally elevated stress concentrations. High stresses may occur in the buckled regions leading to local yielding in the perfect structure, which slightly reduces the predicted buckling strength. Similarly, regions immediately adjacent to the axisymmetric weld depressions are usually subject to very high local stresses, leading to yielding in the vicinity of the weld depressions in GMNIA analyses. Nevertheless, this effect is very minor, though it always reduces the buckling strength.

\section{Conclusions}

The following conclusions may be drawn based on the results of this study:

1) It was shown in the companion paper that the example silos exhibit significant reserves of strength under concentric discharge, by over a factor of two beyond the partial safety factor of the EN 1993-1-6 structural assessment. However, those same designs have been shown to be completely inadequate under the EN 1991-4 eccentric discharge condition. Further, this finding has been shown to be valid throughout a range of slendernesses from very slender to those bordering on squat.

2) The dominant predicted buckling mode in slender silos under the EN 1991-4 eccentric discharge pressures is the predominantly elastic 'midheight' buckling mode. This mode is also widely seen in practice. 
Published in: Journal of Constructional Steel Research, 67(10), 1545-1553.

DOI: http://dx.doi.org/10.1016/j.jcsr.2011.03.027

3) The most common predicted buckling mode of silos with low aspect ratios under eccentric discharge is the predominantly plastic 'base edge' buckling mode. This mode is not known to have been observed in practice. The reason is probably that the EN 1991-4 eccentric discharge model is based on the assumption of parallel-sided eccentric pipe flow, which is unlikely to develop in squatter silos. The computational analysis of squat silos under eccentric discharge therefore requires further study, first in the development of a pressure model for an appropriate unsymmetrical flow pattern and then structural analyses to follow this.

4) The predicted buckling strength of a silo under the EN 1991-4 eccentric discharge pressures is significantly higher when analysed with a geometrically nonlinear analysis (GNA) than with a linear analysis (LBA). The gain in strength may be very large $(\sim 9 \times)$ for smaller flow channels $\left(k_{\mathrm{c}}=r_{\mathrm{c}} / R \approx 0.25\right)$.

5) To obtain the pattern of stresses characteristic of eccentric pipe flow in a geometrically nonlinear analysis, the flow channel is required to be quite large $\left(k_{\mathrm{c}} \geq 0.40\right)$. In linear analyses, a smaller channel with $k_{\mathrm{c}}=0.25$ was sufficient. Geometric nonlinearity therefore produces an important stiffening effect in silos of all aspect ratios, and its mechanics require further study.

6) Axisymmetric weld depressions have been found to lead to significant strength gains, especially for smaller flow channels $\left(k_{\mathrm{c}} \leq 0.40\right)$. This imperfection form, so deleterious under axisymmetric loading, has been found to increase the circumferential bending stiffness of the shell and to enhance the buckling strength significantly. Only very large flow channels still cause buckling across the flow channel at midheight when weld depressions are present. These findings indicate that different imperfection forms are needed when studying eccentric discharge, and that the underlying assumption of EN 19931-6, that deeper imperfections cause lower buckling loads, is seriously in error for this load condition.

\section{References}

ABAQUS (2009). “ABAQUS Version 6.9” Dassault Systèmes Simulia Corp., Providence, RI, USA. 
Published in: Journal of Constructional Steel Research, 67(10), 1545-1553.

DOI: http://dx.doi.org/10.1016/j.jcsr.2011.03.027

Ayuga F., Guaita M., Aguado P.J. \& Cuoto A. (2001). "Discharge and the Eccentricity of the Hopper Influence on the Silo Wall Pressures." Jrnl of Eng. Mech., ASCE, 127(10), 1067-1074.

Calladine C. R. (1983). "Theory of Shell Structures" Cambridge University Press, Cambridge.

Chen J.F. (1996). "Granular Solid - Structure interaction in Silos" PhD Thesis, The University of Edinburgh, UK.

Chen J.F., Rotter J.M., Ooi J.Y. \& Zhong Z. (2007). "Correlation between the flow pattern and wall pressures in a full scale silo." Engineering Structures, 29, 2308-2320.

Chrisp T.M., Wood J.G.M. \& Blacker M.J. (1988). "Comparison of model and fullscale test results with simplified and finite element analyses of eccentrically discharged silos" Silos - Forschung und Praxis, University of Karlsruhe, Germany.

EN 1991-4 (2006). "Eurocode 1: Actions on Structures, Part 4: Silos and Tanks." European Committee for Normalisation, Brussels.

EN 1993-1-6 (2007). "Eurocode 3: Design of Steel Structures, Part 1-6: Strength and Stability of Shell Structures." Comité Européen de Normalisation, Brussels.

EN 1993-4-1 (2007). "Eurocode 3: Design of Steel Structures, Part 4-1: Silos." Comité Européen de Normalisation, Brussels.

Hampe E. (1987). “Silos, Band 1 - Grundlagen.” VEB Verlag für Bauwerke, Berlin.

Holst J.M.F.G., Ooi J.Y., Rotter J.M. \& Rong G.H. (1999a). "Numerical Modelling of Silo Filling. I: Continuum Analyses.” Jrnl of Eng. Mech., ASCE, 125(1), 94-103.

Holst J.M.F.G., Ooi J.Y., Rotter J.M. \& Rong G.H. (1999b). "Numerical Modelling of Silo Filling. II: Discrete Element Analyses.” Jrnl of Eng. Mech., ASCE, 125(1), 104110. 
Published in: Journal of Constructional Steel Research, 67(10), 1545-1553.

DOI: http://dx.doi.org/10.1016/j.jcsr.2011.03.027

Jenike A.W. (1967). "Denting of Circular Bins with Eccentric Drawpoints" J. of the Struct. Div., ASCE, 93 (ST1) 27-35.

Knödel, P., Ummenhofer, T. \& Schulz, U. (1995). “On the Modelling of Different Types of Imperfections in Silo Shells.” Thin-Walled Structures, 23, 283-293.

Rotter J.M. (1986). "The analysis of steel bins subject to eccentric discharge." Proc. of the $2^{\text {nd }}$ Int. Conf. on Bulk Materials Storage, Handling and Transportation, IEAustralia, Wollongong, 264-271.

Rotter J.M. (1990). "Local inelastic collapse of pressurised thin cylindrical steel shells under axial compression.” Jrnl of Struct. Eng., ASCE, 116(7), 1955-1970.

Rotter J.M. (2001a). "Guide for the Economic Design of Circular Metal Silos.”, Spon Press, London \& New York.

Rotter J.M. (2001b). "Pressures, Stresses and Buckling in Metal Silos containing Eccentrically Discharging Solids." Festschrift Richard Greiner, Celebration volume for the $60^{\text {th }}$ birthday of Prof. Richard Greiner, TU Graz, Austria, October, 85-104.

Rotter J.M. (2006). "Elephant's foot buckling in pressurised cylindrical shells.", Stahlbau, Vol 75, Heft 9, 742-747.

Rotter J.M. \& Teng J.G. (1989). "Elastic stability of cylindrical shells with weld depressions.” Jrnl of Struct. Eng., ASCE, 115(5), 1244-1263.

Rotter J.M. \& Zhang Q. (1990). "Elastic buckling of imperfect cylinders containing granular solids.” Jrnl of Struct. Eng., ASCE, 116(8), 2253-2271.

Sadowski A.J. (2010). "Modelling of Failures in Thin-Walled Metal Silos under Eccentric Discharge." PhD Thesis, The University of Edinburgh, UK. 
Published in: Journal of Constructional Steel Research, 67(10), 1545-1553.

DOI: http://dx.doi.org/10.1016/j.jcsr.2011.03.027

Sadowski A.J. \& Rotter J.M. (2010). “A Study of Buckling in Steel Silos under Eccentric Discharge Flows of Stored Solids.” Jrnl of Eng. Mech., ASCE, 136(6), 769776.

Sadowski A.J. \& Rotter J.M. (2011). "Buckling of very slender metal silos under eccentric discharge.” Engineering Structures, 33(4), 1187-1194.

Sanad A.M., Ooi J.Y., Holst J.M.F.G. \& Rotter J.M. (2001). "Computations of Granular Flow and Pressures in a Flat-Bottomed Silo." Jrnl of Eng. Mech., ASCE, 127(10), 1033-1043.

Yamaki N. (1984). "Elastic Stability of Circular Cylindrical Shells." Elsevier Applied Science Publishers, Amsterdam.

Zhong Z., Ooi J.Y. \& Rotter J.M. (2001). "The Sensitivity of Silo Flow and Wall Stresses to Filling Method.” Engineering Structures, 23, 756-767. 